\title{
ERRATUM
}

\section{Erratum to: Additive Postprandial Glucose-Lowering Effects of Mitiglinide and Sitagliptin in Patients with Type 2 Diabetes Mellitus}

Jin Ah Jung $\cdot$ Kohei Kaku $\cdot$ Jae Hyeon Kim · Jung-Ryul Kim •

Jae-Wook Ko $\cdot$ Soo-Youn Lee $\cdot$ Wooseong Huh

To view enhanced content go to www.advancesintherapy.com

Published online: December 19, 2013

(c) Springer Healthcare 2013

Erratum to: Adv Ther (2013) 30:1018-1029

DOI 10.1007/s12325-013-0072-x

The authors would like to make the following adjustment to the above mentioned article. The

The online version of the original article can be found under doi:10.1007/s12325-013-0072-x.

J. A. Jung · J.-R. Kim · J.-W. Ko · W. Huh Department of Clinical Pharmacology and

Therapeutics, Samsung Medical Center, Seoul, Korea

K. Kaku

Department of Internal Medicine, Kawasaki Medical School, Okayama, Japan

J. H. Kim · W. Huh ( $\square)$

Department of Internal Medicine, Samsung Medical

Center, Sungkyunkwan University School of

Medicine, Seoul, Korea

e-mail: wooseong.huh@samsung.com

S.-Y. Lee

Department of Laboratory Medicine and Genetics,

Samsung Medical Center, Sungkyunkwan

University, Seoul, Korea

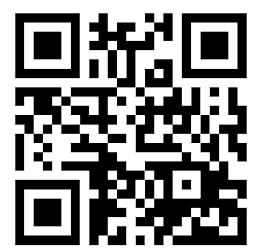

Enhanced content for Advances in Therapy

articles is available on the journal web site:

www.advancesintherapy.com incorrect figure was printed as Fig. $3 \mathrm{~d}$ and the corrected version is shown below. The figure legend is correct in the original article.

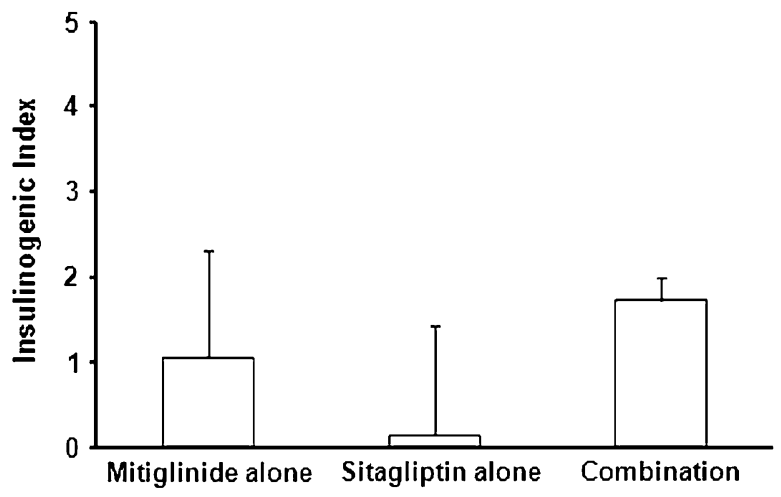

